\title{
MENGENAL PAKET HEADER PADA IP VERSI 4 DEDI SATRIA \\ 175100009
}

Fakultas Komputer

dedisatria.student@umitra.ac.id

\begin{abstract}
Internet protocol versi 4 atau $\operatorname{IPv} 4$ adalah Jenis jaringan yang digunakan di dalam protokol jaringan TCP / IP menggunakan protokol IP versi 4. Panjang totalnya adalah 32-bit dan secara teoritis dapat mengatasi hingga 4 miliar host komputer atau lebih tepatnya 4.294.967.296 host di seluruh dunia, jumlah host diperoleh dari 256 (diperoleh dari 8 bit) dipangkat 4 (karena terdapat 4 oktet) sehingga nilai maksimal dari alamat IP versi 4 adalah 255.255.255.255 dimana nilai dihitung dari nol sehingga nilai host yang dapat ditampung adalah 256x256x256x256 $=4.294 .967 .296$ host, ketika host yang ada di seluruh dunia melebihi kuota tersebut maka dibuatlah IP versi 6 atau IPv6. Contoh IP versi 4 alamat adalah 192.168.0.3
\end{abstract}

Kata Kunci : Mengenal Paket Header Pada Ip Versi 4 


\section{A. PENDAHULUAN}

B. Paket-paket data dalam Internet Protocol (IP) dikirim dalam bentuk datagram yang terdiri atas Header yang berukuran 20 hingga 60 byte dan Data yang berukuran 8 hingga 65515 byte. Pada artikel sebelumnya mengenai "Tips Mudah Subnetting" telah dibahas bahwa IP terdiri atas dua versi, yaitu IP versi 4 dan IP versi 6 dimana setiap versi memiliki Header dengan fungsi yang berbeda.

C. Pada artikel kali ini akan lebih menekankan untuk pembahasan mengenai Paket IP versi 4, sedangkan Paket IP versi 6 akan dibahas pada artikel berikutnya bersamaan dengan cara Decoding Paket IP versi 4 dan 6. Gambar dibawah ini merupakan bentuk format Header dari Paket IP versi 4.

\section{PEMBAHASAN / STUDI KASUS}

1. Berdasarkan geografisnya, jaringan komputer terbagi menjadi Jaringan wilayah lokal atau Local Area Network (LAN), Jaringan wilayah metropolitan atau Metropolita $n$ Area Network (MAN), dan Jaringan wilayah luas atau Wide
Network (WAN). Jaringan wilayah lokal]] merupakan jaringan milik pribadi di dalam sebuah gedung atau tempat yang berukuran sampai beberapa 1 - 10 kilometer. LAN seringkali digunakan untuk menghubungkan komputer-komputer pribadi dan stasiun kerja (workstation) dalam kantor suatu perusahaan atau pabrik-pabrik untuk memakai bersama sumberdaya (misalnya pencetak (printer) dan saling bertukar informasi. Sedangkan Jaringan wilayah metropolitan merupakan perluasan jaringan LAN sehingga mencakup satu kotayang cukup luas, terdiri atas puluhan gedung yang berjarak $10-50$ kilometer. Kabel transmisi

yang digunakan adalah kabel serat optik (Fiber Optic). Jaringan wilayah luas Merupakan jaringan antarkota, antar propinsi, antar negara, bahkan antar benua. Jaraknya bisa mencakup seluruh dunia, misalnya jaringan yang menghubungkan semua bank di Indonesia, atau jaringan yang menghubungkan semua kantor Perwakilan Indonesia di seluruh dunia. Media transmisi utama adalah komunikasi lewat satelit, tetapi banyak yang mengandalkan 
koneksi serat optik antar negara.

\section{E. ID SECURITY}

QWTD4452377-ASP-5244107

\section{F. KESIMPULAN}

jumlah alamat menggunakan 32 bit sehingga jumlah alamat unik yang didukung terbatas yaitu 4.294.967.296 atau lebih dari 4 miliar alamat IP saja. NAT hanya mampu memperlambat penggunaan tak berujung jumlah alamat IPv4, tapi tetap saja, karena pada dasarnya IPv4 menggunakan 32 bit sehingga tidak mengimbangi pertumbuhan dunia internet.

\section{G. DISKUSI}

Saya bersama teman saya bernama Rudi mendiskusikan tentang contoh ini dengan sangat baik Hasil diskusi dari materi ini adalah ....( minimal 150 kata )

\section{H. REFERENCE}

[1] O. M. Febriani and A. S. Putra, "Sistem Informasi Monitoring Inventori Barang Pada Balai Riset Standardisasi Industri Bandar Lampung," J. Inform., vol. 13, no. 1, pp. 90-98, 2014.

[2] A. S. Putra, "Paperplain: Execution Fundamental Create Application With Borland Delphi 7.0 University Of Mitra Indonesia," 2018.

[3] A. S. Putra, "2018 Artikel Struktur Data, Audit Dan
Jaringan Komputer," 2018.

A. S. Putra, "ALIAS

MANAGER USED IN

DATABASE DESKTOP

STUDI CASE DB DEMOS."

[5] A. S. Putra, "COMPREHENSIVE SET OF PROFESSIONAL FOR DISTRIBUTE COMPUTING."

[6] A. S. Putra, "DATA ORIENTED RECOGNITION IN BORLAND DELPHI 7.0."

[7] A. S. Putra, "EMBARCADERO DELPHI XE 2 IN GPUPOWERED FIREMONKEY APPLICATION."

[8] A. S. Putra, "HAK ATAS KEKAYAAN INTELEKTUAL DALAM DUNIA TEKNOLOGY BERBASIS REVOLUSI INDUSTRI 4.0."

[9] A. S. Putra, "IMPLEMENTASI PERATURAN

PERUNDANGAN UU. NO 31

TAHUN 2000 TENTANG

DESAIN INDUSTRI

BERBASIS INFORMATION TECHNOLOGY."

[10] A. S. Putra, "IMPLEMENTATION OF PARADOX DBASE."

[11] A. S. Putra, "IMPLEMENTATION OF TRADE SECRET CASE STUDY SAMSUNG MOBILE PHONE."

[12] A. S. Putra, "IMPLEMENTATION

PATENT FOR APPLICATION WEB BASED CASE STUDI WWW. PUBLIKLAMPUNG. COM."
A.
S.
Putra, "IMPLEMENTATION SYSTEM FIRST TO INVENT 
IN DIGITALLY INDUSTRY."

A. S. Putra, "MANUAL REPORT \& INTEGRATED DEVELOPMENT

ENVIRONMENT BORLAND DELPHI 7.0."

[15] A. S. Putra, "PATENT AS RELEVAN SUPPORT RESEARCH."

[16] A. S. Putra, "PATENT FOR RESEARCH STUDY CASE OF APPLE. Inc."

[17] A. S. Putra, "PATENT PROTECTION FOR APPLICATION INVENT."

[18] A. S. Putra, "QUICK REPORT IN PROPERTY PROGRAMMING."

[19] A. S. Putra, "REVIEW CIRCUIT LAYOUT COMPONENT

REQUIREMENT ON ASUS NOTEBOOK."

[20] A. S. Putra, "REVIEW TRADEMARK PATENT FOR INDUSTRIAL TECHNOLOGY BASED 4.0."

[21] A. S. Putra, "TOOLBAR COMPONENT PALLETTE IN OBJECT ORIENTED PROGRAMMING."

[22] A. S. Putra, "WORKING DIRECTORY SET FOR PARADOX 7."

[23] A. S. Putra, "ZQUERY CONNECTION

IMPLEMENTED

PROGRAMMING STUDI CASE PT. BANK BCA Tbk."

[24] A. S. Putra, D. R. Aryanti, and I. Hartati, "Metode SAW (Simple Additive Weighting) sebagai Sistem Pendukung Keputusan Guru Berprestasi (Studi Kasus: SMK Global
Surya)," in Prosiding Seminar Nasional Darmajaya, 2018, vol. 1, no. 1, pp. 85-97.

[25] A. S. Putra and O. M. Febriani, "Knowledge Management Online Application in PDAM Lampung Province," in Prosiding International conference on Information Technology and Business (ICITB), 2018, pp. 181-187.

[26] A. S. Putra, O. M. Febriani, and B. Bachry, "Implementasi Genetic Fuzzy System Untuk Mengidentifikasi Hasil Curian Kendaraan Bermotor Di Polda Lampung," SIMADA (Jurnal Sist. Inf. dan Manaj. Basis Data), vol. 1, no. 1, pp. 21-30, 2018.

[27] A. S. Putra, H. Sukri, and K. Zuhri, "Sistem Monitoring Realtime Jaringan Irigasi Desa (JIDES) Dengan Konsep Jaringan Sensor Nirkabel," IJEIS (Indonesian J. Electron. Instrum. Syst., vol. 8, no. 2, pp. 221-232.

[28] D. P. Sari, O. M. Febriani, and A. S. Putra, "Perancangan Sistem Informasi SDM Berprestasi pada SD Global Surya," in Prosiding Seminar Nasional Darmajaya, 2018, vol. 1, no. 1, pp. 289-294. 